\title{
Digital security vulnerabilities and threats implications for financial institutions deploying digital technology platforms and application: FMEA and FTOPSIS analysis
}

\author{
Abeeku Sam Edu ${ }^{\text {Corresp., } 1}$, Mary Agoyi ${ }^{2}$, Divine Agozie ${ }^{3}$ \\ 1 Management Information Systems, Cyprus International University, Nicosai, Cyprus \\ 2 Information Technology, Cyprus International University, Nicosia, Cyprus \\ 3 Management Information Systems, Cyprus International University, Nicosia, Cyprus \\ Corresponding Author: Abeeku Sam Edu \\ Email address: asedu@ug.edu.gh
}

Digital disruptions have led to the integration of applications, platforms, and infrastructure. They assist in business operations, promoting open digital collaborations, and perhaps even the integration of the Internet of Things (IoTs), Big Data Analytics, and Cloud Computing to support data sourcing, data analytics, and storage synchronously on a single platform. Notwithstanding the benefits derived from digital technology integration (including loTs, Big Data Analytics, and Cloud Computing), digital vulnerabilities and threats have become a more significant concern for users. We addressed these challenges from an information systems perspective and have noted that more research is needed identifying potential vulnerabilities and threats affecting the integration of IoTs, BDA and CC for data management. We conducted a step-by-step analysis of the potential vulnerabilities and threats affecting the integration of IoTs, Big Data Analytics, and Cloud Computing for data management. We combined multi-dimensional analysis, Failure Mode Effect Analysis, and Fuzzy Technique for Order of Preference by Similarity for Ideal Solution to evaluate and rank the potential vulnerabilities and threats. We surveyed 234 security experts from the banking industry with adequate knowledge in loTs, Big Data Analytics, and Cloud Computing. Based on the closeness of the coefficients, we determined that insufficient use of backup electric generators, firewall protection failures, and no information security audits are high-ranking vulnerabilities and threats affecting integration. This study is an extension of discussions on the integration of digital applications and platforms for data management and the pervasive vulnerabilities and threats arising from that. A detailed review and classification of these threats and vulnerabilities are vital for sustaining businesses' digital integration. 
1 Digital security vulnerabilities and threat implications for financial institutions deploying digital technology platforms and applications: FMEA and FTOPSIS analysis

Corresponding Author:

Abeeku Sam Edu ${ }^{1}$

Via Mersin 10, Nicosia, 99258, Cyprus

Email address: asedu@ug.edu.gh

\begin{abstract}
Digital disruptions have led to the integration of applications, platforms, and infrastructure. They assist in business operations, promoting open digital collaborations, and perhaps even the integration of the Internet of Things (IoTs), Big Data Analytics, and Cloud Computing to support data sourcing, data analytics, and storage synchronously on a single platform. Notwithstanding the benefits derived from digital technology integration (including IoTs, Big Data Analytics, and Cloud Computing), digital vulnerabilities and threats have become a more significant concern for users. We addressed these challenges from an information systems perspective and have noted that more research is needed identifying potential vulnerabilities and threats affecting the integration of IoTs, BDA and CC for data management. We conducted a step-by-step analysis of the potential vulnerabilities and threats affecting the integration of IoTs, Big Data Analytics, and Cloud Computing for data management. We combined multi-dimensional analysis, Failure Mode Effect Analysis, and Fuzzy Technique for Order of Preference by Similarity for Ideal Solution to evaluate and rank the potential vulnerabilities and threats. We surveyed 234 security experts from the banking industry with adequate knowledge in IoTs, Big Data Analytics, and Cloud Computing. Based on the closeness of the coefficients, we determined that insufficient use of backup electric generators, firewall protection failures, and no information security audits are high-ranking vulnerabilities and threats affecting integration. This study is an extension of discussions on the integration of digital applications and platforms for data management and the pervasive vulnerabilities and threats arising from that. A detailed review and classification of these threats

and vulnerabilities are vital for sustaining businesses' digital integration.
\end{abstract}

Abeeku Sam Edu ${ }^{1}$, Mary Agoyi ${ }^{2}$, Divine Agozie ${ }^{3}$

${ }^{1}$ Management Information Systems, Cyprus International University, Nicosia, Cyprus

Information Technology, Cyprus International University, Nicosia, Cyprus

${ }^{3}$ Management Information Systems, Cyprus International University, Nicosia, Cyprus 
41 Emerging and ubiquitous digital applications have created opportunities for industries to combine

42

43

44

45

46

47

48

49

50

51

52

53

54

55

56

57

58

59

60

61

62

63

64

65

66

67

68

69

70

71

72

73

74

75

76

77

78

79

80

81

82

83

84

85

86 technologies to improve operations through open digital interoperability, scalability, and interdependence for digital platforms and applications collaboration (Kebande, Karie \& Venter, 2017). Digital open collaboration has made it possible for applications, tools, and platforms to merge or synchronize successfully with other applications. Recent studies have identified that emerging digital applications such as the Internet of Things (IoTs), Big Data Analytics (BDA), and Cloud Computing (CC) can synchronize to support data sourcing, data analytics, and storage on a single platform (Stergiou et al., 2018a). For example, IoT applications such as radiofrequency identification devices (RFID) and other actuators are primarily used to source data from different fields to support BDA for data processing and insights (Yang et al., 2017). CC provides access to shared resources which enable IoTs data collection for real-time data analysis (Atlam et al., 2018). The concept of digital disruptions has led firms to integrate digital applications and platforms capabilities to promote business values.

Accordingly, financial service operations have been largely influenced by digital applications and platforms to build innovative services and ultimately to increase revenue. For most banks, the need to improve data sourcing and insight creation from data plus their ability to store large volumes of customer data has led to the adoption of IoTs, BDA and CC for financial service operations. Feher and Varga (2017) posited that "the changing role of branches, mobile and phone-based services and products and services" have also contributed to the drive towards ubiquitous platforms and applications. Specifically, adopting the IoTs as the "Bank of Things" has helped commercial banks use automated teller machine kiosks to directly interact with customers' mobile phones to easily withdraw money without using a debit or credit card. IoTs connected devices are valuable for transmitting customers' financial transactions. This in turn allows financial institutions to collect, exchange, and create insight from each transatction. According to Cybersecurity Observatory Finder (2020), "Bank of Things (BoTs) is the material infrastructure that facilitates the billions of data transfers that take place every day". Most banks have also acknowledged that the amount of data being generated has increased enormously due to different sources of collecting data. As such, data have become the most vital asset for banks to effect changes for financial services operations. The focus for banks is the ability to create value, insight and leverage from data assets. Most banks have therefore construed big data into "a greater scope of information, new kinds of data and analysis, real-time information, data influx from new technologies, modern media, large volumes of data, the latest buss word and data from social media" (Forest et al., 2014). New digital technologies have further classified data into volumes, variety, velocity, veracity and value. Personal data and data from daily financial transactions have been optimized using big data analytical tools to create new financial business models, collaborations among employees, fraud detection, optimizing financial operations and customer-focused services. Commercial and retail banks use big data analytics tools such as data mining, query and reporting, data visualization tools, and streaming analytics, to analyze data for specific business models and operational improvements. Cloud computing infrastructures are used by approximately $89 \%$ of banks globally as of 2015 (Hon \& Millard, 2018). Although most banks were initially hesitant to transfer core data to the cloud, the deployment of cloud services is now accepted by commercial banks to support operations. The use of cloud computing services can provide continuous banking services across branches and integrate customer data or information in all branches. Virtual cloud computing services have been used to support the IoTs and BDA, allowing them to have digital scalability, collaborations, interoperability, interdependence, and data management processes within a digital ecosystem.

Peer] Comput. Sci. reviewing PDF | (CS-2020:12:56721:4:1:NEW 23 Jun 2021) 
87

88

89

90

91

92

93

94

95

96

97

98

99

100

101

102

103

104

105

106

107

108

109

110

111

112

113

114

115

116

117

118

119

120

121

122

123

124

125

126

127

128

129

130

131

132

Despite the benefits of integrating digital applications for collaboration, scalability and costefficiency, these applications are complex (Yang et al., 2017; Heavin \& Power, 2018). Studies have indicated that insufficient standardization, heterogeneity, Internet availability, and infrastructure limit the success of digital integration for data management (Kache \& Seuring, 2015). At the heart of these complexities are digital security risks and vulnerabilities. Digital ecosystem interactivities are perpetually affected by threats and vulnerabilities as a result of network connectivity for data transmission and storage via the Internet (Manogaran et al., 2018). Consequently, firms relying on Internet accessibility for digital platforms, and applications interactivity for data management constantly deal with digital security threats and vulnerabilities. The dependence on emerging digital innovations leaves businesses prone to more digital security attacks. These risks stem from the combination of threats within the digital environment. Studies have suggested that digital security risks and vulnerabilities are a result of threats from digital platform usage, the physical environment, people, and an organization's digital ecosystem (OECD, 2015). These dangers affect data integrity, confidentiality, and availability, preventing them from integrating successfully into emerging digital platforms.

Attempts made by IoTs, BDA, and CC to address digital security attacks, digital resources, and the environment have minimized these effects in a number of ways (Yan et al., 2020; Xu et al., 2020; Xu et al., 2019). A cursory review of these approaches in information system (IS) research leads to either technical or managerial perspectives of related security attacks and vulnerabilities (Flores, Antonsen \& Ekstedt, 2014; Singh, Gupta \& Ojha, 2014; Joshi \& Singh, 2017). Again, attempts to address digital security vulnerabilities presented by these applications have been treated independently specific to platforms or application deployment (Sicari et al., 2015; Chang, Kuo \& Ramachandran, 2016). There is little research on the implications of potential vulnerabilities and threats for digital technology integration of IoTs, BDA, and CC in data management (Cherdantseva et al., 2016). There is also an insufficient understanding of how to address risk when integrating these three applications (Choo et al., 2018). We sought to understand the potential vulnerabilities and threats arising from integrating IoTs, BDA, and CC applications to provide security managers with a better awareness of threats against digital interdependence on a single platform.

Assessing digital security threats and vulnerabilities requires continuous efforts to identify, analyze, and measure the attacks with appropriate security management techniques. Bojanc and Jerman-blaz (2008) suggested that the attempt to assess the impact of digital security risks and vulnerabilities should include identifying and assessing loss caused by successful attacks. It should also include decisions to mitigate or reduce the operational risk. Similarly, Chen and Zhao (2013) advocated that security risk assessment must broadly identify the security environment and the accompanying risks issues. Steps must be taken to ensure comprehensive analysis, measurement, and control of the potential risk failures for digital technology resources. Implementing these steps incorporates the probability of identifying risks to the digital systems, detecting the extent of the impact, the severity of potential incidents, procedures for minimizing security controls, and monitoring approved controls' efficacy (Silva et al., 2014; Munodawafa \& Awad, 2018). We examined the literature and identified twenty-seven vulnerabilities and threats that may affect IoTs, BDA, and CC integration. Vulnerabilities and threats were further grouped under access control vulnerabilities, network security attacks, data and information management, infrastructure attacks, security management failures, identity management, and communication security (Li \& Tang, 2013; Kebande et al., 2017; Ouaddah et al., 2017; Kumar, Raj \& Jelciana, 2018; Chang et al.,

Peer] Comput. Sci. reviewing PDF | (CS-2020:12:56721:4:1:NEW 23 Jun 2021) 
133

134

135

136

137

138

139

140

141

142

143

144

145

146

147

148

149

150

151

152

153

154

155

156

157

158

159

160

161

162

163

164

165

166

167

168

169

170

2016). We sought to provide a step-by-step analysis of potential vulnerabilities and threats using multi-dimensional analysis such as Failure Mode Effect Analysis (FMEA) and Fuzzy Technique for Order of Preference by Similarity for Ideal Solution (FTOPSIS). FMEA and FTOPSSIS were used to categorize and prioritize the potential vulnerabilities and threats in IoTs, BDA, and CC integration. Our objectives were:

1. Investigate potential vulnerabilities and threats affecting the integration of IoTs, BDA, and $\mathrm{CC}$ for data management.

2. Evaluate the potential threats and vulnerabilities using FMEA and Fuzzy TOPSIS.

3. Assess the most prevailing threats and vulnerabilities through risk prioritization ranking.

Our study is structured into six main sections. Section 2 reviews potential digital security threats and vulnerability dimensions for IoTs, BDA, and CC integration. Section 3 presents risk management assessment tools, FMEA, and Fuzzy TOPSIS. Section 4 introduces the methodology. Section 5 presents the analysis of our results, and Sections 6 and 7 are a discussion of the results and the conclusion of the study, respectively.

\section{Related Work}

\section{Digital security consideration in loTs, CC and BD integration}

Studies have attempted to classify digital security threats and vulnerabilities for IoTs, CC, and BDA into security risk dimensions. A cursory review of the literature found that the risks influenced the overall benefits of deploying IoTs, CC, and BDA for data management. According to Li and Tang (2013), the identification and prioritization of critical threats and vulnerabilities should find security dimensions to be potential threats to digital platforms and the use of applications. Our study considered these threats when classifying the vulnerabilities and risks for the deployment and use of IoTs, CC and BDA.

\section{Infrastructure (INF) vulnerabilities and attacks}

Digital infrastructure disruptions affect built-in systems in the digital environment. Infrastructure vulnerabilities and risks cause disruption or impact occurrences; they affect hardware and network resources for digital platform interactivity (Li \& Tang, 2013). Vulnerabilities in the infrastructure include IT automated systems failure through hardware malfunctions, natural disasters, or loss of electric power (Xu \& Masys, 2016). Integrating IoTs, BDA, and CC infrastructures support complex data structures; however, they are targets for hackers (Kebande, Karie \& Venter, 2017). Reliance on such digital platform interactivity depends on the security of a pool of shared physicaldigital resources. Failures eventually disrupt the interdependence of software platforms that facilitate interoperability connectivity among IoTs, CC, and BDA (Chatzipoulidis, Michalopoulos $\&$ Mavridis, 2015). Studies have shown that the heterogeneity of digital devices or resources result in a higher likelihood of digital infrastructure failures on a platform that supports interoperability (Ullah et al., 2017). Digital infrastructure failures are further attributed to disruption due to a lack of back-up power, poor patch updates, and the use of infrastructure (Cobb et al., 2018). 
171

172

173

174

175

176

177

178

179

180

181

182

183

184

185

186

187

188

189

190

191

192

193

194

195

196

197

198

199

200

201

202

203

204

205

206

207

208

Security management (SM) failures

Security management failures occur due to the inadequate use of digital security safety measures, insufficient security audits, and poor maintenance of hardware and software assets (Soomro, Shah \& Ahmed, 2016). Failing to adopt a holistic approach to the daily management of security occurrences often disrupts security with digital resources. Poor security measures towards cloud services such as infrastructure as a service (IaaS) in the layers may affect the delivery of services to either a third party or an organization using IoTs and BDA for data management (Jouini \& Rabai, 2017). Security management failures are also attributed to a lack of system security audits, security policy review, and hardware and digital resource maintenance (Le, Hartog \& Zannone, 2018).

\section{Communication security (CS) failures}

A review by Bays et al. (2015) suggested that communication security failures and threats with a lack of security encryption protocols primarily affected digital platform communication. Lack of communication security requirements on IoTs, $\mathrm{CC}$ and $\mathrm{BDA}$ platforms affected data and information integrity, confidentiality and authentication (Martin et al., 2017). The interaction of communication platforms through data and information sharing were compromised, affecting data privacy, integrity and confidentiality. Communication channels were further compromised on a wireless network or interface facilitating the integration of IoTs, CC and BDA (Shu et al., 2016).

\section{Identity management (IDM) failures}

Identity management secures the identification and notification of users' activities on digital platforms and resources. Identity management ensures unique and standardized identification that virtually authenticates users on a secure platform to ensure their safety and security (Ferreira \& Alonso, 2013). Identity management security is affected by the reliability and applicability of IDM systems that control CC platform and provide scalability for BDA, and remote access to IoTs actuators for varied connectivity and usage (Habiba et al., 2014). Habiba et al. (2014) found that identity management security challenges include identity theft, least privileges, elevated privileges, and trust management. Indu, Anand \& Bhaskar (2018) suggested that due to outsourcing and third-party management of digital platform interactivity, identity management security failures or vulnerabilities that arise through IoTs, CC, and BDA must be controlled.

\section{Access control (ACC) failures}

Lack of control of third-party activities through cloud computing sourcing on a platform relying on IoTs to transfer data for big data analytics may result in an unsafe transfer of data (Gharaibeh et al., 2017). Digital trust issues emanating from access to digital platforms may influence an organization's security strategy. Failure to provide rigorous control measures for authenticating and authorizing users' privileges on a digital platform can complicate IoTs, CC and BDA integration (Ouaddah et al., 2017). A systematic analysis of digital security challenges revealed how IoT nodes failed to authenticate authorized access on a cloud platform (Hossain, Fotouhi \& Hasan, 2015), making it vulnerable to attacks. 
209

210

211

212

213

214

215

216

217

218

219

220

221

222

223

224

225

226

227

228

229

230

231

232

233

234

235

236

237

238

239

240

241

242

243

244

245

246

247

Network security (NS) vulnerabilities

Vulnerability attacks occur through the Internet and system network may affect IoTs, CC, and BDA connectivity. These attacks usually affect physical or virtual networks that facilitate the integration of digital interactivity platforms. Singh, Jeong and Hyuk (2016) identified denial of services (DoS), spoofing, distributed denial of service (DDoS), and phishing attacks as network security occurrences affecting access to digital platform integration. These attacks significantly affected IoTs devices that act as a conduit for transmitting data or information through the cloud platform for big data prescriptive analysis (Hossain, Fotouhi \& Hasan, 2015).

\section{Data and information management (DINF) vulnerabilities}

Key policies must define measures to secure and protect data on digital platforms. Examples of vulnerabilities and threat occurrences affecting data and information management on integrated platforms include lack of data scalability and failure to secure data transferability, failure to provide data privacy, lack of data theft prevention, failure to prevent unauthorized access, and including sensitive information in data storage (Kumar et al., 2018; Chang et al., 2016). Few studies have explored the benefits obtained through IoTs, CC, and BDA integration; challenges for managing data on these interactive platforms are on the rise (Cai et al., 2017).

A summary of security dimensions with accompanying vulnerabilities and threats is shown in Table 1. For each digital security dimension, specific failure modes were highlighted as perceived attacks and failures occurring with IoTs, BDA, and CC deployment. Table 1 shows that access control security vulnerabilities are perceived to include external management failures, failure to manage external and internal media removal, control of third party privileges, and failure to control access to digital platforms. Network security issues also occurred due to failed firewalls, unsuccessful prevention of network attacks, missing intrusion detection and prevention systems and a failure to prevent network attacks. Table 1 shows the remaining vulnerabilities and threats defined under each security dimension.

\section{Risk analysis assessment}

Risk analysis is the preliminary step in assessing security risk management procedures (Hinarejos et al., 2018). Risk analysis is a step-by-step procedure using available information to classify and evaluate different sources of potential risks for the use of digital resources. Its success depends on the ability to correctly identify countermeasures to mitigate risks. According to Bojanc and Jerman-blaz (2008), risk management analysis requires the verification of the likelihood that a risk will occur, the likelihood of detecting the risk, and the consequential effect of the risk should it occur. Risk assessment methods must identify the occurrence of vulnerabilities and threats, evaluate and measure their impact, and detect present and future attacks. We reviewed this multidimensional methodology using FMEA and Fuzzy TOPSIS. The two techniques informed the basis of this study and helped to identify the occurrence of risks and vulnerabilities, the severities of such vulnerabilities to digital applications, and the detectability of continuous implications of such security dimensions. 


\section{FMEA and Fuzzy theory application}

249 FMEA has been shown to be a useful analytical tool for evaluating potential risk identification

250

251

252

253

254

255

256

257

258

259

260

261

262

263

264

265

266

267

268

269

270

271

272

273

274

275

276

277

278

279

280

281

282

283

284

285

286

287

288

289

290

291 failures and preventative measures. FMEA is defined by Stamatis (2003) as "an analysis technique for defining, identifying and eliminating known or potential failures, problems, errors and so on from system, design, process and services before they reach the customer". FMEA outlines the process of identifying potential failure modes, causes, effects, and challenges affecting the overall systems, hardware reliability, software applications, and the safety of the system (Kim \& Zuo, 2018). FMEA identifies the potential failure modes based on their criticality to the systems (Kangavari et al., 2015). Measuring the risk priority number (RPN) is determined as the product of Occurrence (Occ), Severity (Sev), and Detection (Det) of a failure mode defined in Equation (Eq) 1. In (Eq) 1, Occ is the frequency of occurrence of the failure mode, Sev is the extent of the effect of the failure mode, and Det is the probability of detecting the failure before it impacts each system. Groups of decision-makers evaluate the three risk parameters (Occ, Sev, and Det) by providing an assessment value with specific scales for each identified failure mode. A high RPN for any failure mode requires adequate attention to provide corrective measures to the system.

$$
R P N=O c c \times \operatorname{Sev} \times \operatorname{Det}
$$

The use of FMEA has been combined with other techniques to improve its efficacy (Liu, Liu \& Liu, 2013). Zadeh (1965) developed the fuzzy set theory to address phenomena characterized by uncertainty or complexities under FMEA conditions. The fuzzy set is able to offer more accurate results with the subjective opinions of FMEA experts. Hadi-Venchec and Aghajani (2013) proposed a fuzzy analysis to examine expert views using linguistic terms to evaluate their independent judgment to control failures. Likewise, Carpitella et al. (2018) proposed a combined multi-criteria approach to support FMEA for a group of experts to optimize maintenance activities. Fuzzy sets are expressed in linguistic terms through fuzzy triangular or trapezoidal numbers (Ramzali, Reza \& Ghodousi, 2015). Linguistic variables represent triangular or trapezoidal fuzzy numbers quantitatively to reflect the responses given by experts (Zadeh, 1965). The linguistic variables are expressed to show the fuzzy ratings for failure modes to determine the weighted criteria of risk factors. The linguistic terms and fuzzy numbers for Occ indicate the probability of a failure mode occurring. Severity explains the level of impact of the failure mode affecting the system. The Det scale also shows the extent to which the system could identify failures modes within a specified period.

Crisp RPN values have been criticized due to the subjectivity of quantifying the linguistic scale although FMEA risk analysis has yielded several results. Focus on fuzzy number aggregation to determine the ranking of RPN for risk factors has been criticized because it does not reflect a fair representation of FMEA group assessments. In response to these limitations, approaches such as a technique for ordering preference by similarity to ideal solution (TOPSIS), analytic hierarchy process (AHP), and data envelopment analysis (DEA) have been proposed in the literature. The TOPSIS and AHP techniques seek to support decision-makers with alternatives under certain conditions (Sun, Wu \& Liu, 2006). In line with the above, we adopted the FTOPSIS multi-criteria decision method to support FMEA in estimating potential vulnerabilities and threats. The FTOPSIS extends traditional TOPSIS to improve the application of linguistic variables for rating criteria for failure modes under FMEA and fuzzy environment (Chen, 2000).

Peer] Comput. Sci. reviewing PDF | (CS-2020:12:56721:4:1:NEW 23 Jun 2021) 


\section{Methodology}

293 We present the research design, the sampling method, questionnaire design, data collection and

294 analysis in the following sections to provide holistic insight into the prevailing threats and

295

296

297

298

299

300

301

302

303

304

305

306

307

308

309

310

311

312

313

314

315

316

317

318

319

320

321

322

323

324

325

326

327

328

329

330

331

332

333 vulnerabilities in IoTs, BDA, and CC integration for data management.

Research design

We adopted a mixed methodology approach combining qualitative and quantitative methodologies (Creswell, 2014). A qualitative method was used to identify and explore the relevant literature detailing different security threats and vulnerabilities affecting the integration of IoTs, CC, and BDA . The survey method was used to administer the questionnaire for data collection. We used FMEA and Fuzzy TOPSIS techniques as the overarching methodology to evaluate, measure, and prioritize vulnerabilities and risk to achieve the objectives of the research. The application of these techniques bridged the qualitative and quantitative analysis.

Sample and sampling technique

Security vulnerabilities and threat occurrences requires respondents to have the technical abilities to manage digital risks and an understanding of their impact on emerging digital platforms and applications. We used the purposive non-probability sampling technique to select experts and collect data. The purposive sampling technique was chosen because of its ability to support the responses from individual respondents. Experts were selected for their knowledge of IoTs, CC, and BDA use in Ghanaian financial institutions. The institutions represented international and domestic financial banks. Digital technologies have supported the financial sector over the past five years and the central bank has been instrumental in supporting the financial sectors with the digitization of banking operations due to legislation (Opoku-Afari, 2019). Therefore, commercial banks in Ghana are using different digital platforms and applications to tailor financial services to improve processes and customer satisfaction. Ghanaian banks were used to investigate digital security vulnerabilities and threats for digital platforms and application deployment within the financial sector.

Questionnaire design and data collection

Our questionnaire was developed based on Goodman's (1996) and the empirical applications of FMEA made by Lin et al. (2014) and Liu et al. (2012). We used a 1-10 linguistic scale (absolutely little influence $=1-2$-points and very high influence $=9-10$ points) to evaluate, measure, and prioritize security vulnerabilities affecting IoTs, BDA, and CC using Occ, Sev, and Det risk parameters. The parameters represent a group decision matrix corresponding to trapezoidal fuzzy numbers constructed to aggregate expert ratings. The linguistic scales were further converted into trapezoidal fuzzy numbers for Occ, Sev, and Det for each decision maker's response. The trapezoidal fuzzy numbers for each decision maker's rating were set within the $[0,1]$ range were $1-2=0 ; 0 ; 0.15 ; 0.2,3-4=0.15 ; 0.2 ; 0.35 ; 0.4,5-6=0.35 ; 0.4 ; 0.55 ; 0.6,7-8=0.55 ; 0.6 ; 0.75 ; 0.8$ and $9-10=0.75 ; 0.8 ; 0.9 ; 1$.

The questionnaires were administered to digital security experts within the financial sector in Ghana, a middle-income Sub-Saharan African country. Data were collected after an initial 
334

335

336

337

338

339

340

341

342

343

344

345

346

347

348

349

350

351

352

353

354

355

356

357

358

359

360

361

362

363

364

365

366

367

368

369

370

371

372

373

374

375

376

assessment of security experts to ascertain their knowledge of IoTs, CC, and BDA deployment and usage. A total of 315 questionnaires were distributed to 23 financial institutions. A total of 255 responses were obtained, of which 234 were considered suitable for the analysis. The remaining 21 questionnaires were eliminated from our analysis due to incomplete responses.

Implementation of data analysis

The FMEA and Fuzzy TOPSIS analysis involved data aggregation for a fuzzy group and weight matrix, a fuzzy normalized matrix, a fuzzy ideal solution, and calculation of coefficient scores closeness. We used FMEA to categorize threats and vulnerabilities by the probability of occurrence, the severity of occurrence, and the extent to which the vulnerabilities were detected. Fuzzy TOPSIS further defined the fuzzy set functions. This enabled us to aggregate experts' responses regarding the occurrence, severity, and detection of digital threats and vulnerabilities. This in turn allowed us to determine the group decision matrix. Considering the subjective nature of expert opinions, the Fuzzy TOPSIS also provided a systematic step to normalize the aggregated responses before determining the criticality of values to rank and prioritize the failure modes under investigation.

The experimental design for the methodology is presented in Figure 1, detailing a step-by-step procedure used to achieve the research objectives. The experimental design provided a statistical procedure for data collection and analysis to yield valid and objective conclusions for this study (Montgomery, 2017). Our experimental design began by identifying experts and collecting data. Experts were identified based on their understanding of the terms and specific data for each digital security criterion. Once this stage was satisfied, the questionnaires were distributed to the appropriate experts within the IT security units. The data reflected the extent to which risks and vulnerabilities occurred and their severity and detectability of the use of IoTs, BDA, and CCs. The second stage of our study transformed the linguistic scales of expert rankings into associated fuzzy trapezoidal numbers using Excel Visual Basic to ensure the reliability of the data set for mathematical modelling. Thus, for the fuzzification of stages 3 to 6 we used Fuzzy TOPSIS mathematical modelling to derive the aggregated fuzzy group matrix, the weighted fuzzy matrix, the normalized fuzzy matrix, the distance for ideal solutions, and the closeness of coefficient scores. We used the closeness of coefficient scores to prioritize and rank the vulnerabilities and threats identified in the context of digital security risks.

\section{Analysis and Results}

\section{Step 1}

Fuzzy set $\mathrm{A}$ is defined as the membership function that includes elements of the universe $\mathrm{X}$ to the unit interval $[0,1]$ (Zadeh, 1965). Accordingly, fuzzy set A in X is characterized by membership function $f_{A}(x)$, the corresponding points for each $\mathrm{X}$ must be real numbers in the interval $[0,1]$ representing $\mathrm{x}$ with set $\mathrm{A}$ (Zadeh, 1965). The value of $f_{A}(x)$ is assumed to be more significant to the membership of $\mathrm{X}$ to set $\mathrm{A}$ if it is closer to 1 . We adapted the trapezoidal fuzzy number $\tilde{A}$ which is represented as $\left(a_{1}, a_{2}, a_{3}, a_{4}\right)$ as shown by Ramzali et al. (2015) in Eq. (2). 


$$
f_{A}(x)=\left\{\begin{array}{cc}
0, & \text { if } x<a_{1} \\
\frac{x-a_{1}}{a_{2}-a_{1}}, & \text { if } a_{1} \leq x \leq a_{2} \\
1, & \text { if } a_{2} \leq x \leq a_{3} \\
\frac{x-a_{4}}{a_{3}-a_{4}}, & \text { if } a_{3} \leq x \leq a_{4} \\
0, & \text { if } x<a_{4}
\end{array}\right.
$$

377

378

379

380

381

382

383

384

385

386

387

388

389

390

391

392

393

394

395

396

397

398

399

400

For any given two positive trapezoidal numbers, $\tilde{A}=\left(a_{1}, a_{2}, a_{3}, a_{4}\right)$ and $\tilde{B}=\left(b_{1}, b_{2}, b_{3}, b_{4}\right)$ with positive real numbers, the basic operations for fuzzy set theory are defined in Eqs. (3) to (6) (Zadeh, 1965; Bojadziev \& Bojadziev, 2007).

$$
\tilde{A} \oplus \tilde{B}=\left[a_{1}+b_{1}, a_{2}+b_{2}, a_{3}+b_{3}, a_{4}+b_{4}\right]
$$

$$
\begin{gathered}
\tilde{A} \ominus \tilde{B}=\left[a_{1}-b_{1}, a_{2}-b_{2}, a_{3}-b_{3}, a_{4}-b_{4}\right] \\
\tilde{A} \otimes \tilde{B}=\left[a_{1} b_{1}, a_{2} b_{2}, a_{3} b_{3}, a_{4} b_{4}\right]
\end{gathered}
$$

$$
\tilde{A} \otimes r=\left[a_{1} r, a_{2} r, a_{3} r, a_{4} r\right]
$$

Again, given $m$ as cross-functional decision makers $D M_{k}(k=1,2, \ldots, m)$ in a FMEA team is responsible for evaluating a set of $n$ failure modes $F M_{i}(i=1,2, \ldots, n)$ with respect to Occurrence, Severity, and Detection risk factors. Therefore, $a_{i j 1}^{k}, b_{i j 2}^{k}, c_{i j 3}, d_{i j 4}^{k}$ are the fuzzy ratings provided by each $D M_{k}$ to evaluate $F M_{i}$ for Occ, Sev, and Det expressed in Eqs. (7), (8), and (9).

$$
O c c=\left(a_{i j 1}^{k}, b_{i j 2}^{k}, c_{i j 3}^{k}, d_{i j 4}^{k}\right)
$$

$$
\operatorname{Sev}=\left(a_{i j 1}^{k}, b_{i j 2}^{k}, c_{i j 3}^{k}, d_{i j 4}^{k}\right)
$$

$$
\text { Det }=\left(a_{i j 1}^{k}, b_{i j 2}^{k}, c_{i j 3}^{k}, d_{i j 4}^{k}\right)
$$

The aggregated fuzzy group decision matrix was derived from Ghoushchi, Yousefi, and Khazaeili (2019) as formulated in Eq. (10). Given that $\widetilde{F M}_{\mathrm{I}}=\mathrm{DM}$ assessment of $\widetilde{F M}_{\mathrm{I}}(i=1,2, \ldots, \mathrm{m})$ with respect to Occ, Sev, and Det risk factors. The trapezoidal values for Occ, Sev, and Det are calculated for each failure mode under their respective dimensions.

$$
\widetilde{F M}_{i}=\left(\tilde{A}_{i j}=\frac{1}{k} * \sum_{k}^{l} a_{i j 1}^{k}, \tilde{B}_{i j}=\frac{1}{k} * \sum_{k}^{l} b_{i j 2}^{k}, \tilde{C}_{i j}=\frac{1}{k} * \sum_{k}^{l} c_{i j 3}^{k}, \tilde{D}_{i j}=\frac{1}{k} * \sum_{k}^{l} d_{i j 4}^{k}\right)
$$

Similarly, each aggregated fuzzy weight denoted as $\tilde{w}_{j}$ was derived using Eq. (11) with respect to Occ, Sev, and Det factors for each failure mode by each $D M_{k}$. 


$$
\tilde{w}_{j}=\left(w_{j 1}, w_{j 2}, w_{j 3}, w_{j 4}\right)=\left(\tilde{w}_{1}=\frac{w_{j 1}}{k}, \tilde{w}_{2}=\frac{w_{j 2}}{k}, \tilde{w}_{3}=\frac{w_{j 3}}{k}, \tilde{w}_{4} \frac{w_{j 4}}{k}\right)
$$

401

402

403

404

405

406

407

$$
\tilde{r}_{i j}=\left\{\begin{array}{l}
\left(\frac{a_{i j}}{d^{+}}, \frac{b_{i j}}{d^{+}}, \frac{c_{i j}}{d^{+}}, \frac{d_{i j}}{d^{+}}\right) \text {if } \mathrm{j} \text { is a benefit attribute } \\
\left(\frac{a_{j}}{d_{i j}}, \frac{a_{j}}{c_{i j}}, \frac{a_{j}}{b_{i j}}, \frac{a_{j}^{-}}{a_{i j}}\right) \text { if } \mathrm{j} \text { is a cost attribute }
\end{array}\right.
$$

408

409

$$
\begin{aligned}
& \quad d_{j}^{+}=\max \text { of } d_{i j} \text { if } j \text { is a benefit attribute } \\
& a_{j}^{-}=\min \text { of } a_{i j} \text { if } j \text { is a cost attribute }
\end{aligned}
$$

$$
\tilde{z}_{i j}=w_{j} \cdot \tilde{r}_{i j}
$$

410 Where $\tilde{r}_{i j}=\left(\frac{a_{j}^{-}}{a_{i j}}, \frac{a_{j}^{-}}{c_{i j}}, \frac{a_{j}^{-}}{b_{i j}}, \frac{a_{j}^{-}}{a_{i j}}\right)$ as described in Eq. (13).

411

412

413

414

415

416

417 Where

\section{Step 3}

In the next stage we computed the fuzzy ideal positive and negative solution in Eqs. (17) to (23) (Carpitella et al., 2018). The Fuzzy Positive Ideal Solution (FPIS) and Fuzzy Negative Ideal Solution (FNIS) are further defined in Eq. (17) and (18), respectively (Chen, 2000).

$$
\begin{gathered}
V^{*}=\left(\tilde{z}_{i 1}^{*}, \tilde{z}_{i 2}^{*}, \ldots \tilde{z}_{i j}^{*}\right) \\
V^{-}=\left(\tilde{z}_{i 1}^{-}, \tilde{z}_{i 2}^{-}, \ldots \tilde{z}_{i j}^{-}\right)
\end{gathered}
$$

$$
\begin{gathered}
\tilde{z}_{i j}^{*}=\max \tilde{v}_{i j}\left(\max a_{i j}, \max b_{i j}, \max c_{i j}, \max d_{i j}\right) \\
\tilde{z}_{i j}^{-}=\min \tilde{v}_{i j}\left(\min a_{i j}, \min b_{i j}, \min c_{i j}, \min d_{i j}\right)
\end{gathered}
$$


418

419

420

421

422

423

$$
d(\tilde{A}, \tilde{B}) \sqrt{\frac{1}{4}\left[\left(a_{1}-b_{1}\right)^{2}+\left(a_{2}-b_{2}\right)^{2}+\left(a_{3}-b_{3}\right)^{2}+\left(a_{4}-b_{4}\right)^{2}\right]}
$$

424

425

426

427

Furthermore, the fuzzy ideal solution for each alternative $d_{i}$ is then aggregated for the whole set of failure modes for related distances $d^{*}$ and $d^{-}$by Eqs. (22) and (23). Table 3 shows the result of a fuzzy ideal solution for each failure mode.

$$
\begin{aligned}
\operatorname{FPIS}\left(d^{*}\right)=\sum_{j=1}^{n} d\left(\tilde{z}_{i j}\right) i=1, \ldots, n & \\
\operatorname{FNIS}\left(d^{-}\right) & =\sum_{j=1}^{n} d\left(\tilde{z}_{i j}\right) i=1, \ldots, n
\end{aligned}
$$

428

429

430

431

432

433

434

435

436

437

438

439

440

441

442

443

444

445

446

447

448

449

\section{Step 4}

Failure mode rankings are finally computed using the closeness of coefficient (CC) in Eq. (24). The final results are shown in Table 4 and indicates the closeness of coefficient score rankings for all vulnerabilities under each dimension (Javadian et al., 2009).

$$
C C_{i}=\frac{F N I S}{F N I S+F P I S}
$$

\section{Discussion}

The corresponding fuzzy numbers were calculated using the aggregated group matrix for Occ, Sev, and Det for each vulnerability and threat identified by the experts. The normalized decision matrix was calculated (Table 2) before the final ranking of the vulnerabilities and threats. The results for the final steps are shown in Table 4 and delineate the risk priority ranking for all vulnerabilities and threats using the closeness of coefficient scores. We found:

i. Twenty-seven perceived failure modes constituting threats and vulnerabilities affecting the integration of IoTs, BDA, and CC (Table 1).

ii. Using the closeness of coefficient scores, we identified 13 of the 27 vulnerabilities affecting the success of IoTs, BDA, and CC integration (Table 4). The closeness of coefficient scores for these vulnerabilities were all above 0.5. This included failure to control infrastructure (0.511092), lack of security policy review (0.521654), digital platforms compatibility failures (0.531005), lack of infrastructure update and patching (0.532621), external management access control (0.566476), lack of policy paper on digital security safety (0.587907), unsuccessful prevention of network attacks (0.596003), no identification of third-party identity (0.667483), no verification of users' true identity 
450

451

452

453

454

455

456

457

458

459

460

461

462

463

464

465

466

467

468

469

470

471

472

473

474

475

476

477

478

479

480

481

482

483

484

485

486

487

488

489

490

491

492

493

494

495

(0.688226), lack of encryption control management (0.70801), failure of firewall protection (0.818448), and lack of backup electric generator $(0.838898)$.

The closeness of coefficient score is indicated by a score closer to or farther from one and implies that vulnerabilities and risk failure modes are ranked from highest to lowest impact. A risk with a high closeness of coefficient is a potential failure significantly affecting the IoTs, BDA, and CCs integration. All vulnerabilities with a closeness of coefficient scores closer to one require more attention during corrective actions to the system. Table 4 and Figure 2 show "lack of backup electric generator (INF4) under infrastructure risk dimension" with the highest closeness coefficient score of 0.8388 followed by "failure of firewall protection (NS1) under network security dimension" with a score of 0.818 and "lack of information security audit (SM1) under security management practices" with a score of 0.735 . These vulnerabilities and risks potentially disrupt interconnectivity and safety and impact of IoTs, BDA, and CC. The future of digital platforms, applications interactivity, and collaborations depend on addressing associated vulnerabilities such as information security audits and firewall protections (Mahmoud et al., 2016). According to Chatzipoulidis, Michalopoulos, and Mavridis (2015), digital platforms sustainability depends on the level at which general digital infrastructure is exposed to vulnerabilities. In that regard, Silva et al. (2014) reported that not having a backup electric generator creates vulnerability in an otherwise sustainable digital infrastructure.

Our results suggested that no encryption control management (CS1), not securing a user's true identity (IDM1), and not identifying third parties (IDM2) are the next potential threats associated with communication security and identity management. Notably, the risks associated with communication security was viewed as a challenge to digital platform collaborations (Soomro et al., 2016; Silva et al., 2014). Bays et al. (2015) confirmed that failing to ensure security encryption protocols affected digital platform communication. Identity theft and elevated privileges for digital platform use jeopardize the security of identity management. The sustainability of cloud supporting services for BDA and IoTs depends on the effectiveness of identity management security systems within digital platforms interactions (Habiba et al., 2014).

Table 4 and Figure 2 illustrate the remaining vulnerabilities and risks failures with three failure modes under data and information management dimensions; these represent the least ranked threats. Failures of digital configuration with digital systems (DINF4), failures related to software functionality on platforms (DINF3), and reliability of digital platforms (DINF2) were ranked $25^{\text {th }}$, $26^{\text {th }}$, and $27^{\text {th }}$ with coefficient scores of $0.332896,0.257042$, and 0.114851 , respectively. These were identified as vulnerabilities or failures to digital integration that did not affect IoTs, BDA, and $\mathrm{CC}$ deployment. This also suggests an improvement in the integration of IoTs, BDA, and CC to support the use of data and information for decision making (Ardolino et al., 2018). In contrast, Stergiou et al. (2018b) observed an increasing gap in privacy and security issues with data management as a result of integrating IoTs and CC technologies. Applying results above suggests that specific attention should focus on vulnerabilities and risks with the closeness of coefficients scores from 0.8 to 0.5 .

\section{Conclusions}

We sought to provide a comprehensive view of the implications of digital technology integration for both research and practice. We also sought to identify potential digital security threats and vulnerabilities with IoTs, BDA, and CC platform integration to support data management.

Most IS studies have not investigated digital security consequences in IoTs, BDA, and CC using FMEA and FTOPSIS techniques. We provided a review of identifying vulnerabilities and threats

Peer] Comput. Sci. reviewing PDF | (CS-2020:12:56721:4:1:NEW 23 Jun 2021) 
496 likely to affect IoTs, BDA, and CC integration. We also proposed a multi-criteria approach to 497 evaluate the effect of integration holistically. As recognized in this study, research on the 498 vulnerabilities and risks of emerging technologies have been focused on a single platform or 499 application and have independently assessed specific IoTs, BDA, or CC issues (Sicari et al., 2015; 500 Choo et al., 2018; Bhathal and Singh, 2019). Our study provides a holistic theoretical approach 501 towards digital technology integration and its potential impact on digital risk management 502 governance. We offer insight into the various potential vulnerabilities and threats to data 503 management when integrating IoTs applications, BDA, and CC platforms.

504 The integration of IoTs, BDA and CC capabilities support data source, insight, storage, and 505 knowledge sharing; however, vulnerabilities and threats significantly influence their success. 506 Hence, controlling their vulnerabilities is more critical than focusing only on how they benefit 507 businesses. The results of our study should be used by IT risk managers to assist in identifying 508 vulnerabilities for IoTs, BDA, and CC deployment. The use of FMEA and FTOPSIS alongside 509 other robust digital risk management approaches can be adopted by IT risk managers to support 510 decision-making criteria on the criticality of ranking vulnerabilities to improve information 511 security analysis. IT risk managers should pay greater attention to firewall protection, reliable 512 power and security audit management to reduce recurring attacks on data due to the complexities 513 of IoT, BDA, and CC integration. Our results suggest that internal and external security measures 514 must adequately protect IoT, BDA and CC infrastructure from curtailing frequent attacks from 515 internal and third-party users.

516 Continuous improvement within the digital ecosystems allows emerging technologies to integrate 517 and promote digital interdependence, interoperability, scalability, and collaboration (Edu, Agoyi 518 \& Agozie, 2020). It is essential to identify potential complexities accompanying the integration of 519 digital technology applications and platforms. We sought to understand the digital security risks 520 facing the integration of IoTs, BDA, and CC deployment. We identified twenty-seven potential 521 vulnerabilities and threats affecting this process. We used closeness of coefficient scores and found 522 that lack of backup electric generator, firewall protection failure, lack of information security audit, 523 lack of encryption control management, and not securing users' true identity were critical.

524 Prioritizing vulnerabilities helps with reducing or managing potential digital security risks 525 emanating from digital technology integration. Accordingly, the use of multi-criteria risk 526 management approaches also allows firms and IT security managers to holistically provide 527 corrective actions when digital security fails.

528 Our findings highlight digital security risk management implications for IoTs, BDA, and CC 529 integration.

530 Our study is limited by its reliance on security experts from financial institutions as their views 531 may not reflect the views of experts from different industries using IoTs, BDA, and CC 532 deployment. Secondly, IoTs, BDA, and CC integration is still an emerging area and generalizing 533 these findings may lead to insufficient conclusions. Additional studies should increase the sample 534 size with IT security experts from different institutions whose responses to the digital security 535 dimensions can be generalized. The findings of this study are limited to vulnerabilities and threats 536 identified in the literature, hence responses from experts reflect the analysis of the results.

537 The integration of these digital technologies are still developing so future research should 538 investigate and empirically validate the relationship and commonalities among the vulnerabilities 539 and identified threats. Future studies should consider exploring other potential vulnerabilities and 540 threats not mentioned in this study since digital security risks are multi-faceted. The data used for 
541 this study included perceptual views from security experts to generate research findings. Although

542 perceptual data is encouraged in survey research, the use of operational data detailing 543 vulnerabilities and threats from system logs, audit trails, and daily transactions or operational 544 activities could further provide validity with digital security risk management. A combination of 545 operational and perceptual data from audit trails or records from system logs could enhance future 546 findings. Lastly, future research can look at other emerging vulnerabilities and threats emanating 547 from the integration of BDA, blockchain technologies, and cloud computing.

548

\section{Acknowledgements}

550

551

552

553

554

555

556

557

558

559

560

561

562

563

564

565

566

567

568

569

570

571

572

573

574

575

576

577

578

579

580

581

582

583

584

The authors wish to express their sincere appreciation to the heads of the banking units and the officials at the digital and security banking units for their voluntary participation in this study.

\section{References}

Ardolino M, Rapaccini M, Saccani N, Gaiardelli P, Ruggeri C, Ardolino M, Rapaccini M, Saccani N, Gaiardelli P. 2018. The role of digital technologies for the service transformation of industrial companies. International Journal of Production Research 56:2116-2132. DOI: 10.1080/00207543.2017.1324224.

Atlam HF, Alenezi A, Alharthi A, Walters RJ, Wills GB. 2018. Integration of cloud computing with the internet of things: Challenges and open issues. In: IEEE International Conference on Internet of Things, IEEE Green Computing and Communications, IEEE Cyber, Physical and Social Computing, IEEE Smart Data, iThings-GreenCom-CPSCom-SmartData 2017. 670-675. DOI: 10.1109/iThings-GreenCom-CPSCom-SmartData.2017.105.

Bays LR, Oliveira RR, Barcellos MP, Gaspary LP, Mauro Madeira ER. 2015. Virtual network security: threats, countermeasures, and challenges. Journal of Internet Services and Applications 6:1-19. DOI: 10.1186/s13174-014-0015-z.

Bhathal GS, Singh A. 2019. Big Data: Hadoop framework vulnerabilities, security issues and attacks. Array 1:1-8. DOI: 10.1016/j.array.2019.100002.

Bojadziev G, Bojadziev M. 2007. Fuzzy logic for business, finance and management. Inc. River Edge, NJ, USA: World Scientific Publishing Company.

Bojanc R, Jerman-blaz B. 2008. An economic modelling approach to information security risk management. International Journal of Information Management 28:413-422. DOI: 10.1016/j.ijinfomgt.2008.02.002.

Cai H, Xu B, Jiang L, Vasilakos A V. 2017. IoT-Based Big Data Storage Systems in Cloud Computing: Perspectives and Challenges. IEEE Internet of Things Journal 4:75-87. DOI: 10.1109/JIOT.2016.2619369.

Carpitella S, Certa A, Izquierdo J, Fata MCLF. 2018. A combined multi-criteria approach to support FMECA analyses: A real-world case. Reliability Engineering and System Safety 169:394-402. DOI: 10.1016/j.ress.2017.09.017.

Chang V, Kuo Y, Ramachandran M. 2016. Cloud computing adoption framework: A security framework for business clouds. Future Generation Computer Systems 57:24-41. DOI: 10.1016/j.future.2015.09.031.

Chatzipoulidis A, Michalopoulos D, Mavridis I. 2015. Information infrastructure risk prediction through platform vulnerability analysis. Journal of Systems and Software 106:28-41. DOI: 10.1016/j.jss.2015.04.062.

Peer] Comput. Sci. reviewing PDF | (CS-2020:12:56721:4:1:NEW 23 Jun 2021) 
585

586

587

588

589

590

591

592

593

594

595

596

597

598

599

600

601

602

603

604

605

606

607

608

609

610

611

612

613

614

615

616

617

618

619

620

621

622

623

624

625

626

627

628

629

630

Chen C. 2000. Extensions of the TOPSIS for group decision-making under a fuzzy environment. Fuzzy Sets and Systems 114:1-9.

Chen G, Zhao D. 2013. Model of Information Security Risk Assessment based on Improved Wavelet Neural Network. Journal of Networks 8:2093-2100. DOI: 10.4304/jnw.8.9.20932100 .

Cherdantseva Y, Burnap P, Blyth A, Eden P, Jones K, Soulsby H, Stoddart K. 2016. A review of cybersecurity risk assessment methods for SCADA systems. Computers \& Security 56:127. DOI: 10.1016/j.cose.2015.09.009.

Choo KKR, Bishop M, Glisson W, Nance K. 2018. Internet- and cloud-of-things cybersecurity research challenges and advances. Computers and Security 74:275-276. DOI: 10.1016/j.cose.2018.02.008.

Cobb C, Sudar S, Reiter N, Anderson R, Roesner F, Kohno T. 2018. Computer security for data collection technologies. Development Engineering 3:1-11. DOI: 10.1016/j.deveng.2017.12.002.

Creswell JW. 2014. Research Design: Qualitative, Quantitative and Mixed Methods Approaches. Sage Publications Ltd.

Edu SA, Agoyi M, Agozie D. 2020. Integrating Digital Innovation Capabilities Towards Value Creation. International Journal of Intelligent Technologies 16:1-16.

Feher P, Varga K. 2017. Using Design Thinking to Identify Banking Digitization Opportunities Snapshot of the Hungarian Banking System. Association for Information Systems 39:151168.

Ferreira MB, Alonso KC. 2013. Identity management for the requirements of information security. 2013 IEEE International Conference on Industrial Engineering and Engineering Management:53-57. DOI: 10.1109/IEEM.2013.6962373.

Flores WR, Antonsen E, Ekstedt M. 2014. Information security knowledge sharing in organizations: Investigating the effect of behavioural information security governance and national culture. Computers and Security 43:90-110. DOI: 10.1016/j.cose.2014.03.004.

Forest H, Foo E, Rose D, Berenzon D. 2014. Big Data: How it can become a differentiator.

Gharaibeh A, Salahuddin MA, Hussini SJ, Khreishah A, Khalil I, Guizani M, Al-Fuqaha A. 2017. Smart Cities: A Survey on Data Management, Security, and Enabling Technologies. IEEE Communications Surveys and Tutorials 19:2456-2501. DOI: 10.1109/COMST.2017.2736886.

Ghoushchi SJ, Yousefi S, Khazaeili M. 2019. An extended FMEA approach based on the ZMOORA and fuzzy BWM for prioritization of failures. Applied Soft Computing Journal 81:105505. DOI: $10.1016 / \mathrm{j}$.asoc.2019.105505.

Goodman SL. 1996. Design for Manufacturability at Midwest Industries, Harvard Business School, February 2, Lecture.

Habiba U, Masood R, Shibli MA, Niazi MA. 2014. Cloud identity management security issues \& solutions: a taxonomy. Complex Adaptive Systems Modelling 2.

Hadi-Venchec A, Aghajani M. 2013. Failure mode and effects analysis: A fuzzy group MCDM approach. Journal of Soft Computing and Application 2013:1-14. DOI: 10.5899/2013/jsca00016.

Heavin C, Power DJ. 2018. Challenges for digital transformation - towards a conceptual decision support guide for managers. Journal of Decision Systems 0125:1-8. DOI: 10.1080/12460125.2018.1468697.

Hinarejos MF, Almenárez F, Arias-cabarcos P, Ferrer-Gomila J-L, López AM. 2018. RiskLaine:

Peer) Comput. Sci. reviewing PDF | (CS-2020:12:56721:4:1:NEW 23 Jun 2021) 
631

632

633

634

635

636

637

638

639

640

641

642

643

644

645

646

647

648

649

650

651

652

653

654

655

656

657

658

659

660

661

662

663

664

665

666

667

668

669

670

671

672

673

674

675

676
A Probabilistic Approach for Assessing Risk in Certificate-Based Security. IEEE Transactions on Information Forensics and Security 13:1975-1988.

Hon WK, Millard C. 2018. Banking in the cloud: Part 1 - banks' use of cloud services. Computer Law \& Security Review 34:4-24. DOI: 10.1016/j.clsr.2017.11.005.

Hossain M, Fotouhi M, Hasan R. 2015. Towards an Analysis of Security Issues, Challenges, and Open Problems in the Internet of Things. In: World Congress on Services. IEEE, 21-28. DOI: 10.1109/SERVICES.2015.12.

Indu I, Anand PMR, Bhaskar V. 2018. Engineering Science and Technology, an International Journal Identity and access management in a cloud environment: Mechanisms and challenges. Engineering Science and Technology, an International Journal 21:574-588. DOI: $10.1016 /$ j.jestch.2018.05.010.

Javadian N, Kazemi M, Khaksar-Fahime, Amiri-aref M, Kia R. 2009. A General Fuzzy TOPSIS Based on New Fuzzy Positive and Negative Ideal Solution. In: IEEE International Conference on Industrial Engineering and Engineering Management. Hong Kong, China: IEEE, 2271-2274. DOI: 10.1109/IEEM.2009.5373055.

Joshi C, Singh KU. 2017. Information security risks management framework - A step towards mitigating security risks in the university network. Journal of Information Security and Applications 35:128-137. DOI: 10.1016/j.jisa.2017.06.006.

Jouini M, Rabai LBA. 2017. A Security Risk Management Model for Cloud Computing Systems: Infrastructure as a Service. In: Wang G, Atiquzzaman M, Yan Z, Choo K-KR eds. Security, Privacy, and Anonymity in Computation, Communication, and Storage. Cham: Springer International Publishing, 594-608.

Kache F, Seuring S. 2015. Challenges and opportunities of digital information at the intersection of Big Data Analytics and supply chain management. International Journal of Operations and Production Management 37:10-36. DOI: 10.1108/IJOPM-02-2015-0078.

Kangavari M, Salimi S, Nourian R, Omidi L, Askarian A. 2015. An application of failure mode and effect analysis (FMEA) to assess risks in the petrochemical industry in Iran. Iranian Journal of Health, Safety \& Environment 2:257-263.

Kebande VR, Karie NM, Venter HS. 2017. Cloud-Centric framework for isolating Big Data as Forensic Evidence from IoT Infrastructures. In: 1st International Conference on Next Generation Computing Applications (NextComp). Mauritius: IEEE. DOI: 10.1109/NEXTCOMP.2017.8016176.

Khalili-damghani K, Sadi-nezhad S. 2013. A hybrid fuzzy multiple criteria group decisionmaking approach for sustainable project selection. Applied Soft Computing Journal 13:339352. DOI: $10.1016 /$ j.asoc.2012.07.030.

Kim KO, Zuo MJ. 2018. General model for the risk priority number in failure mode and effects analysis. Reliability Engineering and System Safety 169:321-329. DOI: 10.1016/j.ress.2017.09.010.

Kumar PR, Raj PH, Jelciana P. 2018. Exploring Data Security Issues and Solutions in Cloud Computing. Procedia Computer Science 125:691-697. DOI: 10.1016/j.procs.2017.12.089.

Le VH, Hartog J den, Zannone N. 2018. Security and privacy for innovative automotive applications: A survey. Computer Communications 132:17-41. DOI: 10.1016/j.comcom.2018.09.010.

Li M, Tang M. 2013. Information security engineering: A framework for research and practices. International Journal of Computers, Communications and Control 8:578-587. DOI: 10.15837/ijecc.2013.4.579. 
677 Lin Q, Wang D, Lin W, Liu H. 2014. Human reliability assessment for medical devices based on 678 failure mode and effects analysis and fuzzy linguistic theory. Safety Science 62:248-256.

679 DOI: 10.1016/j.ssci.2013.08.022.

680 Liu H, Liu L, Liu N. 2013. Risk evaluation approaches in failure mode and effects analysis: A

681

682

683

684

685

686

687

688

689

690

691

692

693

694

695

696

697

698

699

700

701

702

703

704

705

706

707

708

709

710

711

712

713

714

715

716

717

718

719

720

721

722 10.1016/j.eswa.2012.08.010.

Liu H, Liu L, Liu N, Mao L. 2012. Expert Systems with Applications Risk evaluation in failure mode and effects analysis with extended VIKOR method under fuzzy environment. Expert Systems with Applications 39:12926-12934. DOI: 10.1016/j.eswa.2012.05.031.

Mahmoud R, Yousuf T, Aloul F, Zualkernan I. 2016. Internet of things (IoT) security: Current status, challenges and prospective measures. 2015 10th International Conference for Internet Technology and Secured Transactions, ICITST 2015:336-341. DOI: 10.1109/ICITST.2015.7412116.

Manogaran G, Varatharajan R, Lopez D, Malarvizhi P, Sundarasekar R, Thota C. 2018. A new architecture of the Internet of Things and big data ecosystem for secured smart healthcare monitoring and alerting system. Future Generation Computer Systems 82:375-387. DOI: 10.1016/j.future.2017.10.045.

Martin BA, Michaud F, Banks D, Mosenia A, Zolfonoon R, Irwan S, Schrecker S, Zao JK. 2017. OpenFog Security Requirements and Approaches.

Montgomery DCASU. 2017. Design and Analysis of Experiments. New Jersey: John Wiley and Sons Inc.

Munodawafa F, Awad IA. 2018. Security risk assessment within hybrid data centers: A case study of delay-sensitive applications. Journal of Information Security and Applications 43:61-72. DOI: 10.1016/j.jisa.2018.10.008.

OECD. 2015. Digital Security Risk Management for Economic and Social Prosperity.

Opoku-Afari M. 2019. Digitization in the Banking Sector-Enroute to a Cashless Africa. Accra.

Ouaddah A, Mousannif H, Elkalam AA, Ouahman AA. 2017. Access control in the Internet of Things: Big challenges and new opportunities. Computer Networks 112. DOI: 10.1016/j.comnet.2016.11.007.

Ramzali N, Reza MLM, Ghodousi J. 2015. Safety barriers analysis of offshore drilling system by employing Fuzzy Event Tree Analysis. Safety Science 78:49-59. DOI: 10.1016/j.ssci.2015.04.004.

Shu Z, Wan J, Li D, Lin J, Vasilakos A V., Imran M. 2016. Security in Software-Defined Networking: Threats and Countermeasures. Mobile Networks and Applications 21:764-776. DOI: $10.1007 / \mathrm{s} 11036-016-0676-\mathrm{x}$.

Sicari S, Rizzardi A, Grieco LA, Coen-porisini A. 2015. Security, privacy and trust in Internet of Things: The road ahead. Computer Networks 76:146-164. DOI: 10.1016/j.comnet.2014.11.008.

Silva MM, Gusmao HDPA, Poleto T, Silva CL, Costa APCS. 2014a. A multidimensional approach to information security risk management using FMEA and fuzzy theory. International Journal of Information Management 34:733-740. DOI: 10.1016/j.ijinfomgt.2014.07.005.

Silva MM, Gusmao APH, Poleto T, Silva LC, Costa APCS. 2014b. A multidimensional approach to information security risk management using FMEA and fuzzy theory. International Journal of Information Management 34:733-740. DOI: 10.1016/j.ijinfomgt.2014.07.005. 
723

724

725

726

727

728

729

730

731

732

733

734

735

736

737

738

739

740

741

742

743

744

745

746

747

748

749

750

751

752

753

754

755

756

757

758

759

760

761

762

763

764
Singh AN, Gupta MP, Ojha A. 2014. Identifying factors of organizational information security management. Journal of Enterprise Information Management 27:664-667. DOI: https://doi.org/10.1108/JEIM-07-2013-0052.

Singh S, Jeong Y, Hyuk J. 2016. A survey on cloud computing security: Issues, threats, and solutions. Journal of Network and Computer Applications 75:200-222. DOI: 10.1016/j.jnca.2016.09.002.

Soomro ZA, Shah MH, Ahmed J. 2016. Information security management needs a more holistic approach: A literature review. International Journal of Information Management 36:215225. DOI: 10.1016/j.ijinfomgt.2015.11.009.

Stamatis DH. 2003. Failure Mode and Effect Analysis - FMEA from Theory to Execution. American Society for Quality (ASQ).

Stergiou C, Psannis KE, Gupta BB, Ishibashi Y. 2018a. Security, privacy \& efficiency of sustainable Cloud Computing for Big Data \& IoT. Sustainable Computing: Informatics and Systems 19:174-184. DOI: 10.1016/j.suscom.2018.06.003.

Stergiou C, Psannis KE, Gupta BB, Ishibashi Y. 2018b. Security, privacy \& efficiency of sustainable Cloud Computing for Big Data \& IoT. Sustainable Computing: Informatics and Systems 19:174-184. DOI: 10.1016/j.suscom.2018.06.003.

Stergiou C, Psannis KE, Kim B, Gupta B. 2018c. Secure integration of IoT and Cloud Computing. Future Generation Computer Systems 78:964-975. DOI: 10.1016/j.future.2016.11.031.

Sun S, Wu Q, Liu G. 2006. Multi-level decision-making model for product design based on Fussy set theory. In: 1st International Symposium on Pervasive Computing and Application. IEEE, 841-846. DOI: 10.1109/SPCA.2006.297543.

Ullah F, Asif M, Farhan M, Khalid S, Durrana MY, Jabbar S. 2017. Semantic interoperability for big-data in heterogeneous IoT infrastructure for healthcare. Sustainable Cities and Society 34:90-96. DOI: 10.1016/j.scs.2017.06.010.

Xu T, Masys AJ. 2016. Critical Infrastructure Vulnerabilities: Embracing a Network Mindset. In: Masys AJ ed. Exploring the Security Landscape: Non-Traditional Security Challenges. Cham: Springer International Publishing, 177-193. DOI: 10.1007/978-3-319-27914-5_9.

Xu Y, Ren J, Wang G, Zhang C, Yang J, Zhang Y. 2019. A Blockchain-Based Nonrepudiation Network Computing Service Scheme for Industrial IoT. IEEE Transactions on Industrial Informatics 15:3632-3641.

Xu Y, Ren J, Zhang Y, Member S. 2020. Blockchain Empowered Arbitrable Data Auditing Scheme for Network Storage as a Service. IEEE Transactions on Services Computing 13:289-300.

Yan X, Xu Y, Xing X, Ciu B, Guo Z, Guo T. 2020. Based on an Adaptive Learning Rate and Momentum in IoT. IEEE Transactions on Industrial Informatics 16:6182-6192.

Yang C, Huang Q, Li Z, Liu K, Hu F. 2017. Big Data and cloud computing: innovation opportunities and challenges. International Journal of Digital Earth 10:13-53. DOI: 10.1080/17538947.2016.1239771.

Zadeh LA. 1965. Fuzzy Sets. Information and Control 8:338-353. 


\section{Table 1 (on next page)}

Failure Modes

Digital Security Risk and Vulnerabilities 


\section{Table 1. Failure Modes for Digital Security Risk and Vulnerabilities}

\begin{tabular}{|c|c|}
\hline Dimensions & Failure Modes \\
\hline \multirow{6}{*}{ Access Control (ACC) } & $\begin{array}{l}\text { AC1- External management access control } \\
\text { AC2-Management of removable of internal and external } \\
\text { media risk }\end{array}$ \\
\hline & AC3-Control to third party privileges risk \\
\hline & AC4-Access to external digital platforms control \\
\hline & NS1- Failure of Firewall protection \\
\hline & $\begin{array}{l}\text { NS2- File transfer protocol to authenticate the } \\
\text { communication between devices and networks }\end{array}$ \\
\hline & NS3- Lack of intrusion detection and prevention system \\
\hline \multirow[t]{4}{*}{ Network Security (MS) } & NS4- Lack of preventing network attacks \\
\hline & DINF1- Digital Platforms compatibility failures \\
\hline & DINF2- Reliability of digital platforms \\
\hline & DINF3- Failure of software functionality on platforms \\
\hline \multirow[t]{3}{*}{ Data and Information Management (DINF) } & $\begin{array}{l}\text { DINF4- Failure of digital configuration with a digital } \\
\text { system }\end{array}$ \\
\hline & INF1- Failure to control the use of infrastructure \\
\hline & INF2- Lack of infrastructure update and patching \\
\hline \multirow[t]{5}{*}{ Infrastructure (INF) } & INF3- Software origination and defence failures \\
\hline & INF4- Lack of back-up electric generator \\
\hline & SM1- Lack of information security audit \\
\hline & SM2-Lack of a policy paper on digital security safety \\
\hline & SM3- Lack of maintenance of hardware and software \\
\hline \multirow[t]{3}{*}{ Security Management (SM) } & SM4- Lack of security policies reviews \\
\hline & IDM1- Lack of securing users' true identity \\
\hline & $\begin{array}{l}\text { IDM2- Lack of identifying a third-party identity } \\
\text { IDM3- Notification to system administrator on a user's } \\
\text { identity }\end{array}$ \\
\hline \multirow[t]{3}{*}{ Identity Management (IDM) } & $\begin{array}{l}\text { IDM4- Lack of detecting outsourced party activity and } \\
\text { identity }\end{array}$ \\
\hline & CS1- Lack of encryption control management \\
\hline & CS2- Lack of limited content access to internet \\
\hline Communication Security (CS) & CS3- Lack of safety of electronic mail \\
\hline
\end{tabular}




\section{Table 2 (on next page)}

Normalized Fuzzy Weighted Matrix

Group Weighted Matrix 
1 Table 2. Normalized Group Fuzzy Weighted Matrix

\begin{tabular}{|c|c|c|c|c|c|c|c|c|c|c|c|c|c|}
\hline \multirow[t]{2}{*}{ Dimensions } & \multirow{2}{*}{$\frac{\text { Failure Mode }}{\mathrm{AC} 1}$} & \multicolumn{4}{|c|}{ Occurrence } & \multicolumn{4}{|c|}{ Severity } & \multicolumn{4}{|c|}{ Detection } \\
\hline & & 0.3025 & 0.3665 & 0.5945 & 0.7150 & 0.3385 & 0.4094 & 0.6327 & 0.7550 & 0.2126 & 0.2649 & 0.4863 & 0.5970 \\
\hline \multirow{5}{*}{ Access Control } & $\mathrm{AC} 2$ & 0.3027 & 0.3667 & 0.5946 & 0.7150 & 0.3385 & 0.4082 & 0.6327 & 0.7550 & 0.2086 & 0.2606 & 0.4828 & 0.5970 \\
\hline & $\mathrm{AC} 3$ & 0.3036 & 0.3676 & 0.5951 & 0.7150 & 0.3353 & 0.4018 & 0.6330 & 0.7550 & 0.2100 & 0.2607 & 0.4837 & 0.5970 \\
\hline & $\mathrm{AC} 4$ & 0.3010 & 0.3639 & 0.5937 & 0.7150 & 0.3389 & 0.4078 & 0.6348 & 0.7550 & 0.2109 & 0.2621 & 0.4843 & 0.5970 \\
\hline & NS1 & 0.3059 & 0.3730 & 0.6089 & 0.7150 & 0.3424 & 0.4139 & 0.6389 & 0.7550 & 0.2129 & 0.2658 & 0.4870 & 0.5970 \\
\hline & NS2 & 0.2978 & 0.3597 & 0.5930 & 0.7150 & 0.3378 & 0.4083 & 0.6333 & 0.7550 & 0.2086 & 0.2603 & 0.4822 & 0.5970 \\
\hline \multirow{3}{*}{ Network Security } & NS3 & 0.3070 & 0.3733 & 0.5968 & 0.7150 & 0.3353 & 0.4035 & 0.6321 & 0.7550 & 0.2057 & 0.2566 & 0.4816 & 0.5970 \\
\hline & NS4 & 0.3059 & 0.3699 & 0.5962 & 0.7150 & 0.3398 & 0.4104 & 0.6352 & 0.7550 & 0.2097 & 0.2613 & 0.4844 & 0.5970 \\
\hline & DINF1 & 0.3090 & 0.3752 & 0.5978 & 0.7150 & 0.3341 & 0.4026 & 0.6334 & 0.7550 & 0.2086 & 0.2594 & 0.4848 & 0.5970 \\
\hline \multirow{4}{*}{$\begin{array}{l}\text { Data and Information } \\
\text { Management }\end{array}$} & DINF2 & 0.3031 & 0.3661 & 0.5958 & 0.7150 & 0.3283 & 0.3963 & 0.6305 & 0.7550 & 0.1980 & 0.2480 & 0.4779 & 0.5970 \\
\hline & DINF3 & 0.2971 & 0.3594 & 0.5916 & 0.7150 & 0.3364 & 0.4054 & 0.6336 & 0.7550 & 0.2040 & 0.2545 & 0.4818 & 0.5970 \\
\hline & DINF4 & 0.3031 & 0.3673 & 0.5958 & 0.7150 & 0.3313 & 0.3986 & 0.6320 & 0.7550 & 0.2068 & 0.2579 & 0.4826 & 0.5970 \\
\hline & INF1 & 0.3049 & 0.3687 & 0.5977 & 0.7150 & 0.3371 & 0.4063 & 0.6321 & 0.7550 & 0.2094 & 0.2609 & 0.4824 & 0.5970 \\
\hline \multirow{5}{*}{ Infrastructure } & INF2 & 0.3048 & 0.3682 & 0.5957 & 0.7150 & 0.3387 & 0.4074 & 0.6338 & 0.7550 & 0.2100 & 0.2611 & 0.4837 & 0.5970 \\
\hline & INF3 & 0.3017 & 0.3641 & 0.5950 & 0.7150 & 0.3389 & 0.4070 & 0.6339 & 0.7550 & 0.2090 & 0.2595 & 0.4821 & 0.5970 \\
\hline & INF4 & 0.3158 & 0.3816 & 0.6104 & 0.7150 & 0.3376 & 0.4057 & 0.6332 & 0.7550 & 0.2143 & 0.2656 & 0.4855 & 0.5970 \\
\hline & SM1 & 0.3140 & 0.3801 & 0.6003 & 0.7150 & 0.3409 & 0.4113 & 0.6348 & 0.7550 & 0.2097 & 0.2613 & 0.4844 & 0.5970 \\
\hline & SM2 & 0.3107 & 0.3746 & 0.5987 & 0.7150 & 0.3360 & 0.4042 & 0.6324 & 0.7550 & 0.2109 & 0.2619 & 0.4824 & 0.5970 \\
\hline \multirow{3}{*}{ Security Management } & SM3 & 0.3015 & 0.3632 & 0.5940 & 0.7150 & 0.3360 & 0.4043 & 0.6334 & 0.7550 & 0.2078 & 0.2584 & 0.4833 & 0.5970 \\
\hline & SM4 & 0.3066 & 0.3687 & 0.5957 & 0.7150 & 0.3380 & 0.4063 & 0.6344 & 0.7550 & 0.2093 & 0.2599 & 0.4833 & 0.5970 \\
\hline & IDM1 & 0.3077 & 0.3733 & 0.5972 & 0.7150 & 0.3419 & 0.4129 & 0.6354 & 0.7550 & 0.2114 & 0.2630 & 0.4846 & 0.5970 \\
\hline \multirow{5}{*}{ Identity Management } & IDM2 & 0.3036 & 0.3677 & 0.5960 & 0.7150 & 0.3413 & 0.4119 & 0.6360 & 0.7550 & 0.2142 & 0.2665 & 0.4863 & 0.5970 \\
\hline & IDM3 & 0.2998 & 0.3644 & 0.5931 & 0.7150 & 0.3353 & 0.4048 & 0.6330 & 0.7550 & 0.2118 & 0.2635 & 0.4848 & 0.5970 \\
\hline & IDM4 & 0.2959 & 0.3581 & 0.5900 & 0.7150 & 0.3374 & 0.4072 & 0.6360 & 0.7550 & 0.2101 & 0.2618 & 0.4847 & 0.5970 \\
\hline & $\mathrm{CS} 1$ & 0.3072 & 0.3712 & 0.5969 & 0.7150 & 0.3402 & 0.4095 & 0.6345 & 0.7550 & 0.2152 & 0.2672 & 0.4879 & 0.5970 \\
\hline & $\mathrm{CS} 2$ & 0.3004 & 0.3620 & 0.5924 & 0.7150 & 0.3353 & 0.4035 & 0.6321 & 0.7550 & 0.2139 & 0.2654 & 0.4871 & 0.5970 \\
\hline Communication Security & $\mathrm{CS} 3$ & 0.3030 & 0.3656 & 0.5928 & 0.7150 & 0.3346 & 0.4028 & 0.6317 & 0.7550 & 0.2133 & 0.2651 & 0.4858 & 0.5970 \\
\hline
\end{tabular}




\section{Table 3(on next page)}

Fuzzy Positive and Negative Ideal Solution

Distance 
1 Table 3. Distance for FPIS and FNIS

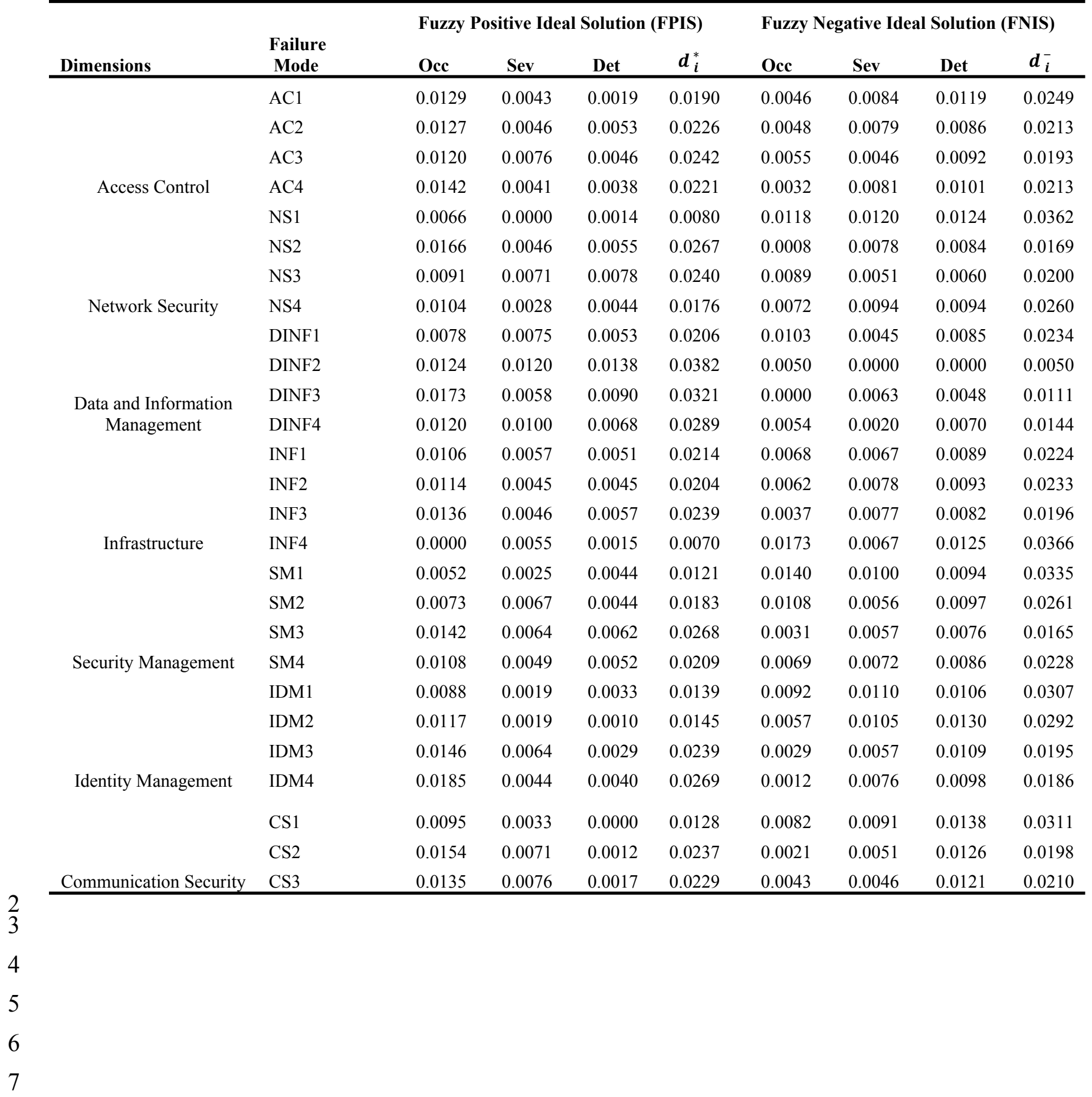




\section{Table 4(on next page)}

Failure Modes Rankings

Rankings 
1 Table 4. Failure Modes Ranking

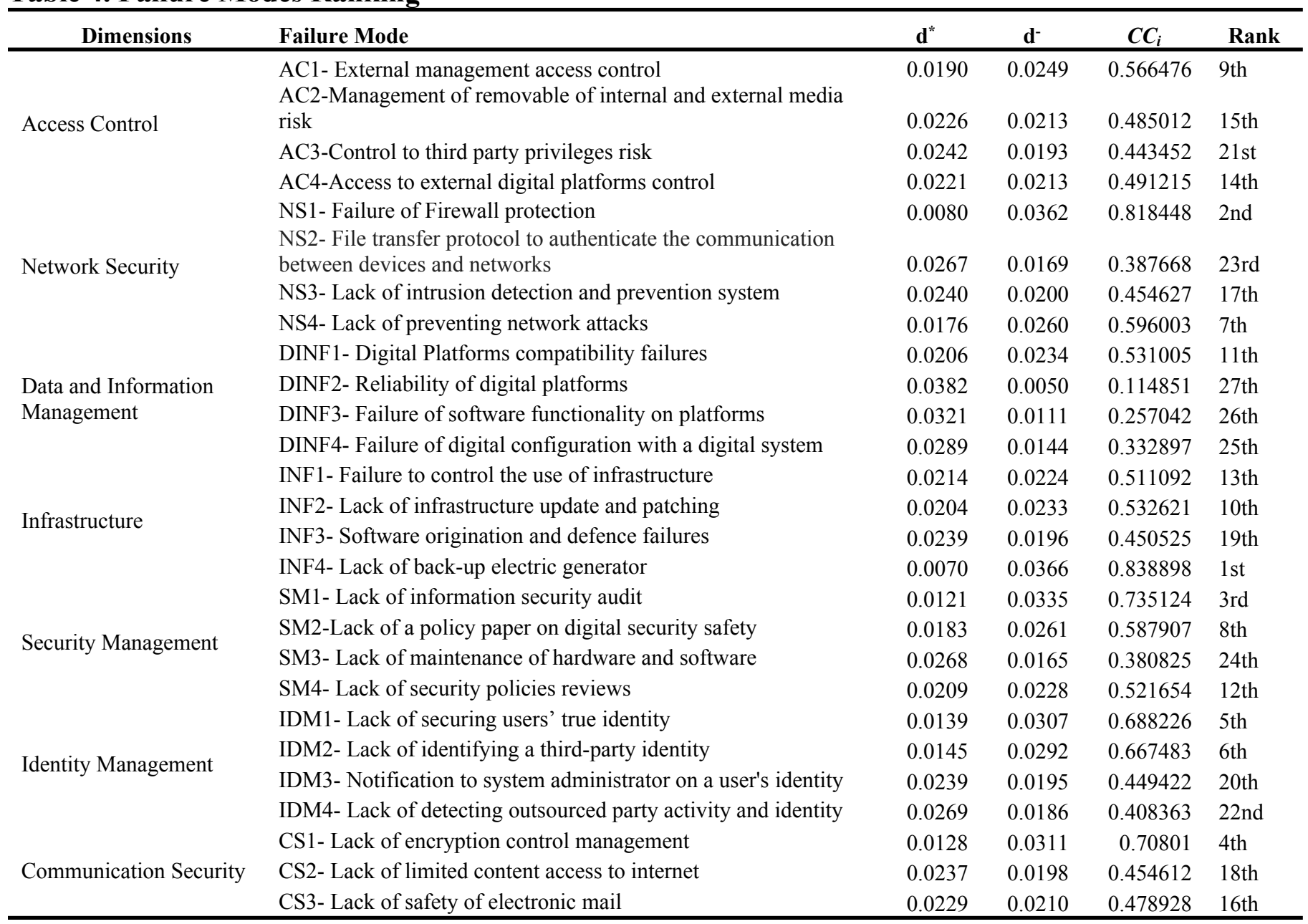


Figure 1

Flow chart of the digital security assessment through FMEA and FTOPSIS 


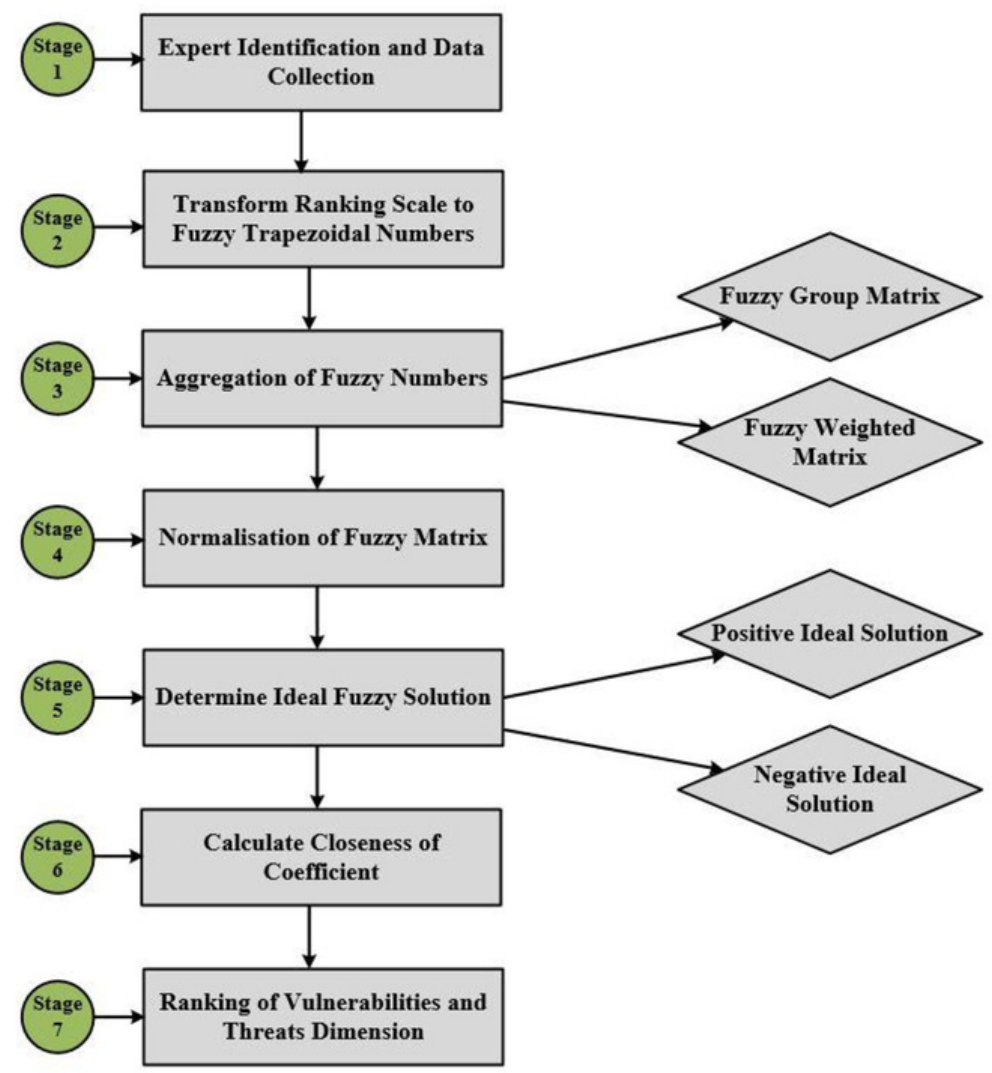

Figure 1: Flow chart of the digital security assessment through FMEA and FTOPSIS 
Figure 2

Closeness of Coefficient Score and Ranking Chart 


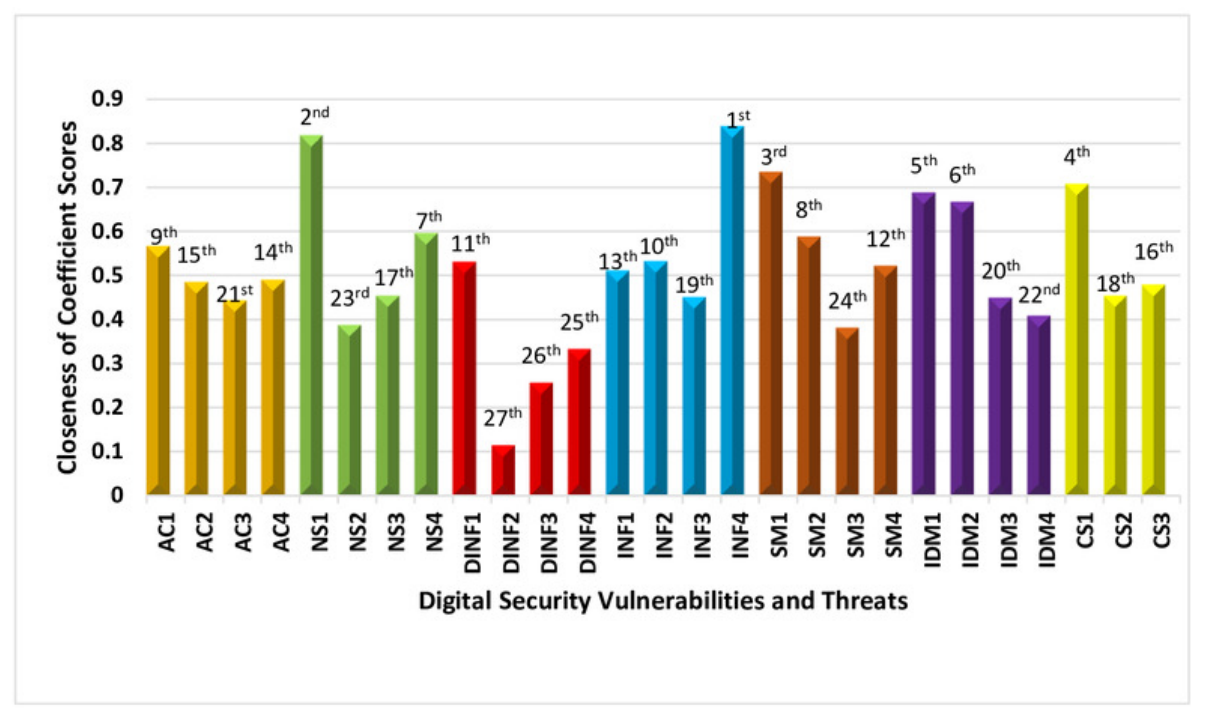

Figure 2. Closeness of Coefficient Score and Ranking Chart 